\title{
Including hope in the treatment scheme-paradigms in the management of patients with cerebral palsy
}

\author{
Ioana Alexandra Pădureț ${ }^{1}$ \\ Received: 1 October 2019 / Accepted: 16 October 2019 / Published online: 29 October 2019 \\ (c) European Society of Human Genetics 2019
}

Book: Children and youth with complex cerebral palsy: Care and Management

Edited by: Laurie Glader and Richard Stevenson

Published by: Mac Keith Press

ISBN: 978-1-909962-98-9

Price: $£ 39.95$ (hardcopy)

As medicine's new and exciting genomic era allows for personalized rather than standardized care, the collaboration between doctors, patients, and their family is of the outmost importance, aiming at social integration and developing a sense of belonging in those afflicted. "Children and Youth with Complex Cerebral Palsy" tackles every important aspect of managing a patient with such a diagnosis, bridging the gap between professional assistance and familial care.

The book starts off nicely, addressing in the first two chapters standard neurological notions and classifications, while offering a brief and to-the-point explanation regarding disease causality and impact.

Afterwards, the main focus are complications associated with cerebral palsy (CP) and managing solutions, referring to but not limited at pharmacological interventions, surgery and therapy. For instance, in chapter 3, treatment options for hypertonia are being presented in the form of a summarizing table, with clear indications, while the paragraphs are used to emphasize all important aspects to consider when opting for either drug therapy or neurosurgical approach. It is enjoyable to read, in chapter 6, physiology and physiopathology notions related to osteoporosis and fractures addressed in a concise manner, allowing for a thorough understanding of normal bone formation and abnormal processes related to $\mathrm{CP}$, without neglecting diagnostic procedures and possible medical therapies.

Ioana Alexandra Pădureț

paduret.alexandra@gmail.com

1 Department of Prenatal Diagnostic, Clinical Hospital of Obstetrics and Gynecology, Cuza Voda, Iasi, Romania
It becomes apparent, as the reading continues, that the authors decided to adopt a rather didactical approach, which I find can be very useful for either a practicing clinician, wishing for a concise review of the available data or a medical trainee, looking to systematize information.

Practical issues related to clinical examination are also being referred to throughout the book. For example, chapter 15 offers a clear overview of different types of seizures, aided by clinical scenarios and clear management instructions.

Notwithstanding the fact that every aspect of the systemic involvement in CP's natural history is presented separately, each chapter playing an important part in understanding the complexity of this disease and the fact that the authors addressed logistic and bureaucratic issues as well, which makes this book stand out are the chapters dedicated to patients' and their families' every day experience. Important aspects regarding decision making, coping mechanisms, and more sensible subjects, such as sexual life and preventing sexual violence, are discussed in the last chapters of the book, making it a valuable instrument for everyone involved in taking care of a patient with CP. It becomes clear that offering the best possible medical care is not enough to unsure life quality and reading about similar experiences might be significant in improving the level of understanding of this disease and most importantly in bringing a sense of belonging and hope to those who need it.

In conclusion, I find "Children and youth with complex Cerebral Palsy-Care and management" to be just what the title promises-a handbook on medical and emotional support, useful for patients and everyone involved in their care.

\section{Compliance with ethical standards}

Conflict of interest The author declares that she has no conflict of interest.

Publisher's note Springer Nature remains neutral with regard to jurisdictional claims in published maps and institutional affiliations. 